\title{
Relationship between bream (Abramis brama) activity and water turbidity in a shallow lake under different season conditions
}

\author{
Joan H. HANSEN, ${ }^{1}$ Jakob BRODERSEN,${ }^{2,3}$ Henrik BAKTOFT, ${ }^{1}$ Christian SKOV ${ }^{1 *}$ \\ ${ }^{1}$ National Institute of Aquatic Resources, Technical University of Denmark (DTU), Vejlsøvej 39, Silkeborg 8600, Denmark; \\ ${ }^{2}$ Department of Fish Ecology and Evolution, Center for Ecology, Evolution and Biogeochemistry, EAWAG Swiss Federal Institute of \\ Aquatic Science and Technology, Seestrasse 79, Kastanienbaum 6047, Switzerland; ${ }^{3}$ Division of Aquatic Ecology and Evolution, \\ Institute of Ecology and Evolution, University of Bern, Baltzerstrasse 6, Bern 3012, Switzerland
}

\begin{abstract}
The foraging activity of large-bodied benthivorous fish has been suggested to be of key importance for maintaining shallow lakes in a turbid state. Since especially the spring ecosystem dynamics determines the successive state of shallow lakes, such impact could depend on seasonality in benthivore activity patterns. However, we do not yet know to what extent the activity of large-bodied benthivorous fish affects lake turbidity across the year. In order to investigate seasonal dynamics in bream activity and its impact on water turbidity under natural conditions, bream daily activity was studied in a small (39 ha) shallow Danish lake using passive biotelemetry technology, i.e. a modified Passive Integrated Transponder (PIT)-tag antenna system. We tracked the activity of 448 benthivorous bream over a period of four years (2012 to 2016) and during the same period wind conditions, water turbidity and temperature was measured. Results showed a clear relationship between bream activity and water turbidity at water temperature below $15^{\circ} \mathrm{C}$ indicating that winter season activity of benthivorous bream may play an important role for maintaining lake ecosystems in a turbid state. Also wind speed and wind direction affected water turbidity, suggesting that wind induced resuspension can be important even in small shallow lakes. This is to our knowledge the first full-scale study under natural conditions to describe how bream activity influence lake turbidity on a day-to-day basis. Our findings also add a seasonal component to previous findings by showing that benthivorous feeding bream have the potential to increase water turbidity also in the winter season and thereby, ultimately, impact ecosystem functioning within shallow lakes.
\end{abstract}

\section{INTRODUCTION}

Many aquatic and terrestrial ecosystems exist in alternative states, whose stabilities are determined by their resistance to environmental change and their resilience (Peterson and Stevenson, 1992; Peterson et al., 1998; Gunderson, 2000; Folke et al., 2004). The mechanisms responsible for the degree of resilience are often understood through consumptive effects, although nonconsumptive effects may be at least as important (Dublin et al., 1990). Non-consumptive effects that may affect

Corresponding author: ck@aqua.dtu.dk

Keywords: Ecosystem engineers; benthivore; foraging activity; bioturbation; resuspension; temperature.

Edited by: Franz Hölker, Leibniz Institute of Freshwater Ecology and Inland Fisheries, Berlin, Germany.

Received: 18 December 2018.

Accepted: 24 April 2019.

This work is licensed under a Creative Commons Attribution NonCommercial 4.0 License (CC BY-NC 4.0).

${ }^{\circ}$ Copyright: the Author(s), 2019

Licensee PAGEPress, Italy

J. Limnol., 2019; 78(2): 259-269

DOI: 10.4081/jlimnol.2019.1883 ecosystem resilience include trampling, burrowing and horning in terrestrial ecosystems (Knapp et al., 1999; Estes et al., 2008; Haynes, 2012) and bioturbation, digging and burrowing in aquatic ecosystems (Moore, 2006). Large-bodied species of such ecosystem engineers (Jones et al., 1997) generally have a higher nonconsumptive per capita effect on the ecosystem than smaller species (Cumming and Cumming, 2003). Moreover, since large-bodied species generally have longer life spans, their population dynamics may not respond fast to ecological changes, which may increase their effect on ecosystem resilience. In shallow lakes, large bodied benthivorous fish are believed to maintain the ecosystem in a turbid state (Scheffer et al., 1993), but many aspects of the actual mechanisms involved, especially regarding seasonal variation, are relatively poorly understood.

Eutrophication has historically had a severe effect on many aquatic ecosystems (Smith, 2003) including lakes (Brönmark and Hansson, 2002) and although many lakes now are in or have completed a phase of reoligotrophication (Jeppesen et al., 2005), changes back towards the original state in several cases appear slow or absent (Ibelings et al., 2007). Eutrophication is associated with an increase in water turbidity mainly caused by increased algal biomass. However, in shallow lakes, turbidity can also be highly influenced by nonconsumptive effects, i.e. by resuspension of sediment particles caused by foraging behaviour of benthivorous 
fish (Breukelar et al., 1994; Zambrano et al., 2001; Parkos et al., 2003). Such resuspension of sediment can potentially influence the structure and functioning of the lake ecosystem in several ways (Scheffer, 1998) by reducing the light penetration through the water column (Roberts et al., 1995; Parkos et al., 2003). This may influence foraging strategies of visual orientated piscivores, i.e. reduce foraging rates, and thereby potentially uncouple trophic top down cascades (Miner and Stein, 1993) and affect dispersal and growth of submerged macrophytes, due to less light available in the water column (Fisher et al., 2013; Gu et al., 2016). Another non-consumptive ecosystem effect of large bodied benthivorous fish is an increase in total phosphorus and nitrogen concentrations due to resuspension, releasing sedimentary nutrients to the water column, which ultimately can result in increased growth of algal biomass (Boström et al., 1982; Andersson et al., 1988; Parkos et al., 2003; Fisher et al., 2013; Gu et al., 2016). Hence, benthivorous fish can have profound effects on other trophic levels and play an important role for maintaining lakes in, or shifting lakes towards a turbid stable state, which may have severe negative impacts on biodiversity as well as ecosystem functioning (Scheffer, 1990).

In northern European lakes, bream (Abramis brama) is a common and abundant freshwater fish (Tammi et al., 1999). Individuals generally display ontogenetic diet shifts, with young bream feeding mainly on planktonic prey and adults mainly feeding on benthivorous prey (Persson and Hansson, 1999, but see Lammens et al., 1987 and Vašek et al., 2003 for exceptions). Adults are specialized benthivorous, foraging by penetrating and probing the sediment, ingesting both food organisms (e.g. insect larvae and worms) and sediment particles (Breukelaar et al., 1994, Persson and Hansson, 1999). Within the buccal cavity, food particles are selectively retained, whereas sediment particles pass the gill raker system and are flushed away in clouds behind the opercula into the water column (Lammens and Hoogenboezem, 1991). The feeding behaviour of large adult bream can therefore cause profound resuspension of lake sediments, decrease sediment stability and release nutrients from the sediment into the water column (Andersson et al., 1988; Meijer et al., 1990; Brukelaar et al., 1994). Due to their large adult size, older bream are generally outside the predatory range of piscivorous fish (Skov et al., 2011), which, in combination with a high longevity (Kottelat and Freyhof, 2007), results in a slow population response to changed environmental conditions. Consequently, bream is a target species in biomanipulation by fish removal, i.e. as a tool for restoration of eutrophic shallow lakes as hypertrophic lakes often include high densities of large adult bream (Jagtman et al., 1990; Søndergaard et al., 2008).
Despite the important role bream have for ecosystem functioning in shallow lakes and as target species in biomanipulation, field studies exploring the direct relationship between bream activity and turbidity are lacking. Instead, most studies that have explored presence $v s$. absence of bream and the related changes in turbidity either in enclosures (Breukelaar et al., 1994) or under natural conditions (Meijer et al., 1990). Moreover, most studies on benthivorous fish have in general focused on summer dynamics and not included any seasonal dynamics in their studies (but see King and Hunt, 1967). As for ectotherms in general, bream activity, such as foraging intensity, is expected to be positively related to temperature. However, telemetry studies have shown considerable activity of lentic freshwater fish, such as bream, also during cold periods in autumn and winter (Jacobsen et al., 2002; Baktoft et al., 2012; Jurajda et al., 2018). This could in turn have implications for seasonal dynamics of water turbidity. The aim of this study is therefore to increase our knowledge about the seasonal dynamics in bream activity and how this impact water turbidity in shallow lakes under natural conditions. To obtain this, we measured bream activity daily for four years using biotelemetry technology, and related this to daily on-site registrations of water turbidity during the same period.

\section{METHODS}

\section{Study system and study period}

The study was conducted in Lake Loldrup, which is $0.39 \mathrm{~km}^{2}$, shallow (mean depth $1.2 \mathrm{~m}$, maximum depth $3.3 \mathrm{~m}$ ), slightly eutrophic (mean Secchi depth $1.1 \mathrm{~m}$ ) and situated in Denmark $\left(56^{\circ} 29^{\prime} \mathrm{N}, 9^{\circ} 26^{\prime} \mathrm{E}\right)$. The lake has an inlet and outlet stream. The fish community is dominated by roach (Rutilus rutilus) and bream, but also includes perch (Perca fluviatilis), pike (Esox lucius), and pikeperch (Sander lucioperca). The study was initiated in June 2012 and terminated in August 2016.

\section{Bream activity}

To track activity of bream we used passive biotelemetry technology, i.e. a modified Passive Integrated Transponder (PIT)-tags combined with an antennae system (Skov et al., 2008).

As part of this and other studies (Skov et al., 2011), pit tagging of bream had been conducted in Lake Loldrup every fall from 2006 to 2015. Bream for tagging were caught in fall by electrofishing, seining and gill netting (emptied at least every second hour). Hereafter, bream were anaesthetized with benzocaine $\left(20 \mathrm{mg} \mathrm{L}^{-1}\right)$, individually measured for total length (nearest $\mathrm{mm}$ ) and body mass (nearest g) before tagged by surgically 
implanting a passive integrated transponder (PIT) tag (Texas Instruments, RI-TRP-RRHP, Plano, TX, USA, half duplex, $134 \mathrm{kHz}, 23.1 \mathrm{~mm}$ long, $3.85 \mathrm{~mm}$ in diameter, 0.6 $\mathrm{g}$ in air) into the body cavity of the fish. Following PIT tagging, fish were allowed to recover until released (3090 minutes) to the lake again. Mortality related to tagging was very rare $(<1 \%)$, which is in line with studies that find no significant effect on fish well-being, including body condition following tagging (Skov et al., 2005). A total of 726 adult bream $(434.5 \pm 62.2 \mathrm{~mm}$, mean total length \pm SD) was tagged between 2006 and 2015. Experimental animal treatment was performed under permission from the Danish Animal Experiments Inspectorate.

Three pair of PIT reading antennae was positioned in the lake in 2012 (Fig. 1). Each antenna is loop shaped and constructed by oxygen free copper loudspeaker cable $\left(2 \times 4 \mathrm{~mm}^{2}\right)$ mounted inside a frame (dimensions $500 \mathrm{~cm}$ x $85 \mathrm{~cm}$ ) of $30 \mathrm{~mm}$ PVC pipe, which are mounted perpendicular to the lake bed by wooden posts. Each pair of antennae was composed of one antenna in the interface between emergent shoreline vegetation and open-water and one antenna on average 30 meter further ashore in the open-water zone (Fig. 1). The antennae as well as the hardware that registered the PIT tags, were powered directly from the power net (two pairs of antennae) or

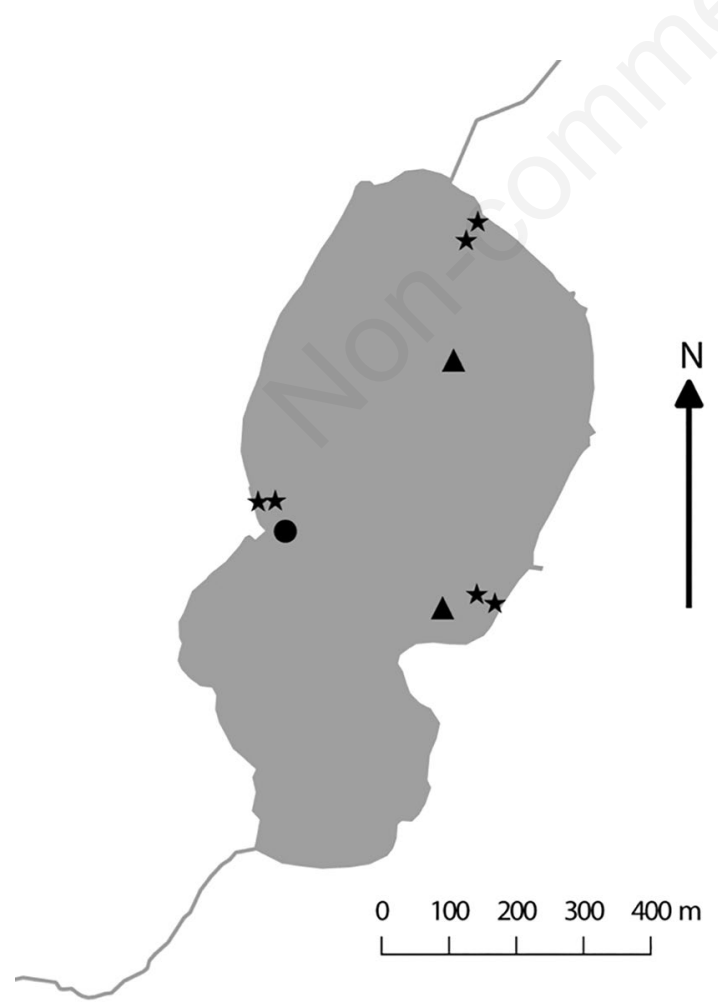

Fig. 1. Lake Loldrup including the position of the six antennae (stars), turbidity logger (circle) and the sites of Secchi depth measurements (triangles). from a small windmill (Rutland, Model 913; 12 volts, 85 watts).

When a tagged bream swims by any of the six antennae placed in the lake (Fig. 1), the PIT-tag is energized and its unique code emitted. This is recorded and transmitted once a day via GPRS Net to a database at DTU Aqua where it is stored together with date, time and the identity of the antenna. As a measure of bream activity levels, we constructed an activity index (hereafter bream activity), based on the number of unique individual bream registered per antennae per hour. The mean number of bream per antenna was calculated per day resulting in a daily estimate, i.e. bream activity.

Efficiency of the antennae, i.e. the amount of time when the antennae was functioning was also evaluated, and only periods where two or more of the six antennae were functioning was included in the analyses. This evaluation was based on so-called "marker tags", placed in the near vicinity of each antenna. This special tag emits a code every hour and we subsequently identified days of malfunctioning as days were no code from the marker tag was registered and, at the same time, no tagged fish were registered. The latter to prevent exclusion of days where it was the marker tag, and not the antenna, that was malfunctioning. The six antennae were functioning $90 \%$ of the time during the study period. Most often it was a single or a pair of antennae that was malfunctioning for a period (rarely more than a few weeks), and more rarely 3 and 4 antennae ( $<4 \%$ of the days) was malfunctioning. The reasons for malfunctions were most often battery failures and typically related to the wind powered pairs of antennae where calm weather prevented the batteries to charge.

\section{Water temperature and turbidity}

Turbidity, the amount of light that is scattered by material in the water, as well as water temperature was measured throughout the study period using AQUAlogger ${ }^{\circledR}$ 210TYT, Aquatec, Basinstroke, UK (300 $\mathrm{mm}$ long $\mathrm{x} 60 \mathrm{~mm}$ in diameter). The turbidimeter was attached to a fixed structure (wooden pole) approximately 0.5 meters below the water surface and measured water turbidity in Formazin Turbidity Units (FTU) and temperature (Fig. 1). Turbidity was measured using optical backscatter, which detect optical scattering of infrared light from suspended matter. The AQUAlogger $\AA$ $210 \mathrm{TYT}$ uses an $880 \mathrm{~nm}$ light source and, within the range of $0-750 \mathrm{FTU}$ it measures turbidity linearly with a deviation of $<2 \%$. To avoid biological growth on the optical window of the logger, it was equipped with an antifouling wiper. Turbidity was measured five times minimum every second hour during the four-year study period from which the daily mean was calculated. The turbidimeter had about 40 days with malfunctioning, i.e. 
$3.38 \%$ of the study period and these days were excluded from the study.

As a way to translate FTU to Secchi depths, we measured Secchi depths at regular intervals from 2013 to 2016. Secchi depths were measured at one of two positions in the lake. However, on two occurrences Secchi depth were measured at both positions at the same day. On these days, a mean of the Secchi depth was used in the relationship between turbidity (FTU) and Secchi depth (Supplementary Tab. 1).

\section{Statistical analyses}

To evaluate the role of bream activity on water turbidity in Lake Loldrup we applied Gamma distributed generalized additive models (GAM). The residuals were checked for absence of auto-correlation and variance homogeneity to meet the assumptions of the model. Prior to fitting the GAMs, Variance Inflation Factors (VIFs) were used to explore collinearity between covariates and only covariates with VIFs below 3 where used in the model (Zuur et al., 2009). This best model was chosen based on a stepwise selection method that optimized explained deviance and Akaike's Information Criterion (AIC). To account for environmental factors that might affect turbidity, we included daily averages of wind speed $\left(\mathrm{m} \mathrm{s}^{-1}\right)$ and wind direction measured by the Danish Meteorological Institute in the vicinity of Lake Loldrup (9 km away; latitude: 56.49 , longitude: 9.57 ).

The following GAM was fitted:

Turbidity $=\alpha+f_{t}$ (Bream activity:Temperature $)+$ $f($ Wind speed $)+f($ Wind direction $)+$ Antenna + Year,

where $\alpha$ is the overall intercept, $f_{t}$ (Bream activity: Temperature) is a smoothing function modelling a tensor product interaction between bream activity and water temperature, $f$ (Wind speed) is a smoothing spline of wind speed, $f$ (Wind direction) is a cyclic cubic regression spline. Antenna is the six antennae situated in the lake and is included in the model to account for antenna specific variation in bream activity and differences in functionality throughout the four years of analysis. Finally, Year is included as a factor to allow between year variation from 2012 to 2016. In order to ensure that only benthivorous feeding bream were included, we exclusively included bream of minimum $300 \mathrm{~mm}$ in the model (Lammens et al., 1987; Persson and Hansson, 1999). Preliminary data visualization revealed that bream activity was extraordinarily high in short periods during spring/ summer each year, which most probably represent spawning behaviour rather than feeding activity. In accordance with Poncin et al. (1996) we define spawning period during spring/early summer as days with water temperature above $14.5^{\circ} \mathrm{C}$ and we set the start and finish of the spawning periods as days where bream activity sudden increased and decreased with minimum $50 \%$ according to the day before or after, respectively (Supplementary Tab. 2, Fig. 2). Since the overarching goal of the study was to explore the general relationship between bream feeding activity and water turbidity, we excluded these data from the analyses.

We preliminary tested if a delay between time of bream activity and water turbidity would produce a better AIC. However, this was not the case and we included bream activity and water turbidity measured on the same day in the model (Supplementary Tab. 3).

In addition to the GAM analysis, temperature dependent bream activity patterns were explored by a correlation between bream activity and the average daily water temperature. Further, a simple correlation was used to illustrate the relationship between FTU turbidity and Secchi depths (Supplementary Tab. 1).

All statistical analyses were carried out using the statistical computing program R (R Core Team, 2016) and the GAM model was performed using the $m g c v$ package (Wood, 2011).
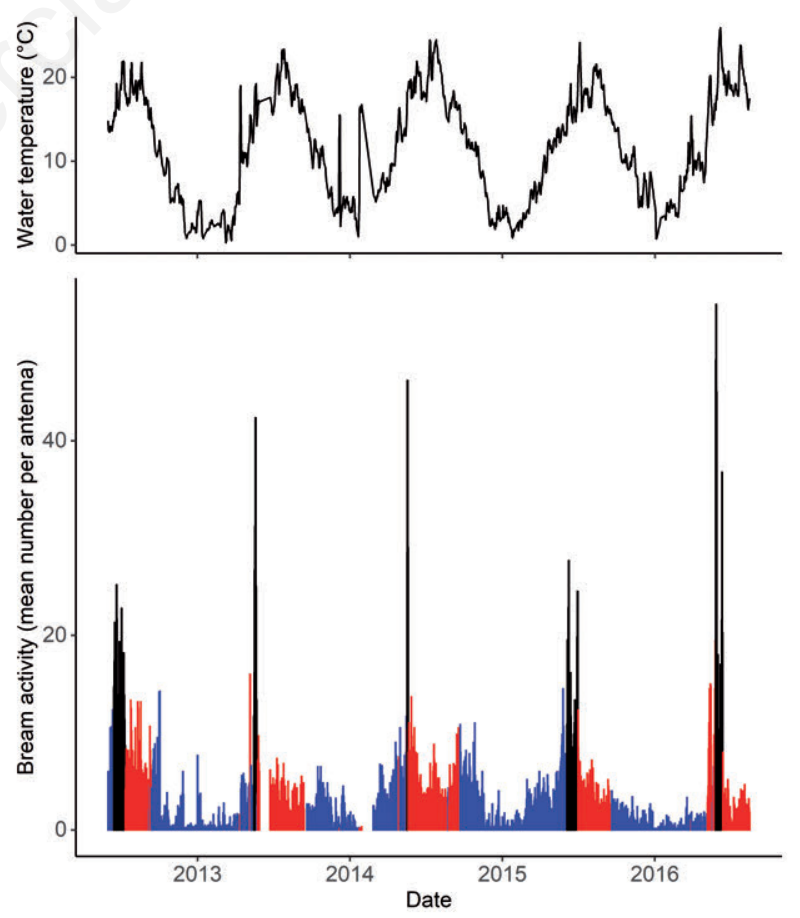

Fig. 2. Daily water temperature (line) and bream activity (mean number of unique individual bream per antenna) during the study period. Blue bars for bream activity shows activity when water temperature is below $15^{\circ} \mathrm{C}$ and red bars with water temperature above $15^{\circ} \mathrm{C}$. No bars illustrate days were data is lacking and black bars indicate days that we define as spawning activity which is not included in the GAM model. See text and Supplementary Tab. 2 for further explanations. 


\section{RESULTS}

From June 2012 to August 2016, a total of $62 \%$ of the pit tagged bream, i.e. 448 different bream $>300 \mathrm{~mm}$ (440.9 $\pm 47.5 \mathrm{~mm}$, mean total length $\pm \mathrm{SD}$ ), were recorded on one or several of the six antennae in Lake Loldrup. Registrations occurred throughout the study period but there was a clear relationship between bream activity and temperature $\left(\mathrm{R}^{2}=0.46\right)$, illustrating higher bream activity during the summer period (Figs. 2 and 3).

As expected there was a clear relationship between FTU and Secchi depth $\left(\mathrm{R}^{2}=0.70\right)$ (Fig. 4), confirming that our one-point high-resolution monitoring of turbidity represent Secchi depth in the lake.

Bream activity affected turbidity, although this effect was influenced by temperature (GAM, $\mathrm{P}<0.001$, Tab. 1, Fig. 5). Indeed, there was an increase in turbidity with increasing temperature, but bream activity appears to result in increased water turbidity when the temperature is relatively low i.e. below approximately $15^{\circ} \mathrm{C}$ (Fig. 5) and at Secchi depths between 60 and $200 \mathrm{~cm}$ (Fig. 4). At higher water temperatures, when Secchi depths were always $<60 \mathrm{~cm}$ (Fig. 4), the relationship between bream activity and turbidity was not as obvious (Fig. 5). Additionally, wind speed and wind direction (Fig. 6) were significant predictors of water turbidity in the model $(\mathrm{P}<0.001$, Tab. 1). Wind speed increased turbidity and wind direction influenced turbidity particular at East and West directions (Fig. 6). Also year and antenna were significant predictors of water turbidity $(\mathrm{P}<0.001$, Tab. 1$)$, which presumably is an expression of variation between year, variation of bream density between years and antenna (not all antenna were operational at all times during the study period).

Tab. 1. Statistical results from the generalized additive model (GAM), Turbidity $=\alpha+f_{t}$ (Bream activity:Temperature $)+f($ Wind speed $)+f($ Wind direction $)+$ Antenna + Year. Deviance explained by this model is $75.1 \%$ and $\mathrm{R}^{2}=0.63$.

\begin{tabular}{lcc}
\hline Categorical variables & F-value & P-value \\
\hline Antenna & 5.09 & $<0.001$ \\
\hline Year & 82.54 & $<0.001$ \\
Smoothing functions & F-value & P-value \\
Bream activity:Temperature & 6.91 & $<0.001$ \\
\hline Bream activity & 3.37 & 0.003 \\
\hline Temperature & 2268.76 & $<0.001$ \\
\hline Wind speed & 26.84 & $<0.001$ \\
\hline Wind direction & 3.74 & $<0.001$ \\
\hline
\end{tabular}

\section{DISCUSSION}

This study highlights the specific influence of variation in activity of bream, a large-bodied ecosystem engineer, on ecosystem state variables that are central for

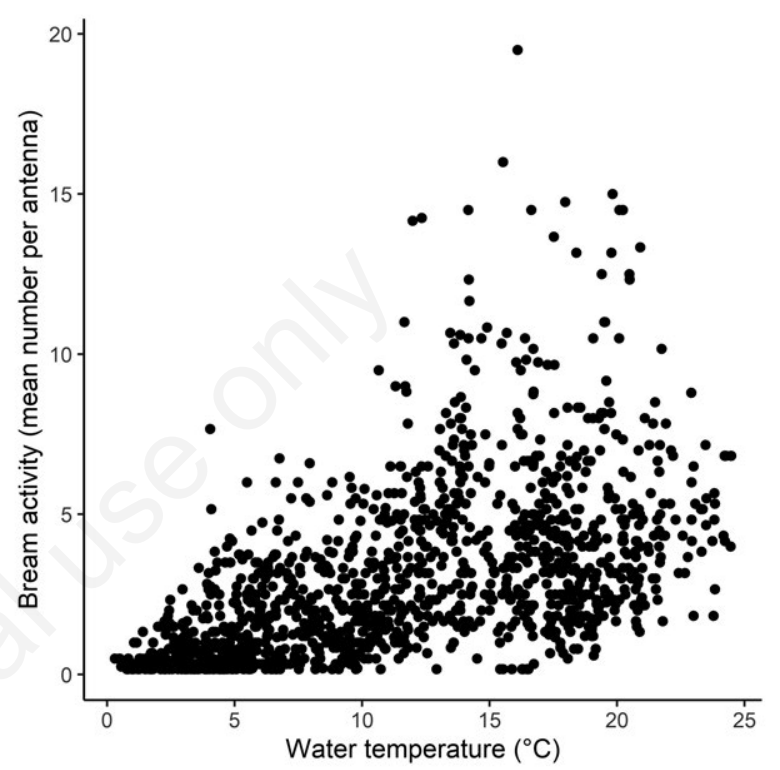

Fig. 3. Relationship between water temperature $\left({ }^{\circ} \mathrm{C}\right)$ and bream activity (mean number of unique individual bream per antenna) $\left(\mathrm{R}^{2}=0.46\right)$. Bream spawning activity is not included in this figure (see text for further explanation).

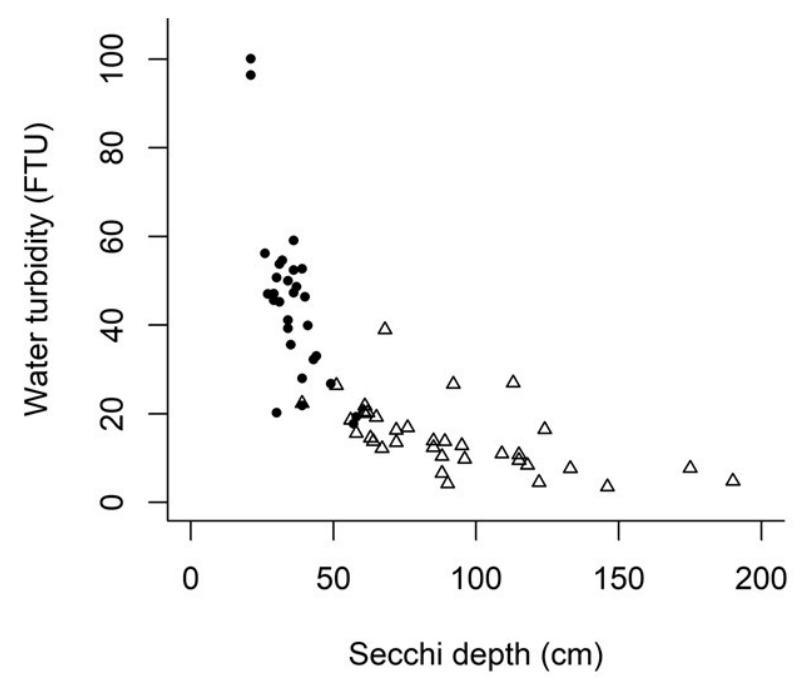

Fig. 4. Relationship between turbidity (FTU) and Secchi depth $(\mathrm{cm})\left(\mathrm{R}^{2}=0.70\right)$ measured in Lake Loldrup from 2013 to 2016 on dates were temperature was above $15^{\circ} \mathrm{C}$ (filled circles) and below $15^{\circ} \mathrm{C}$ (triangles). See Supplementary Tab. 1 for sampling dates. 
ecosystem resilience through non-consumptive mechanisms. More specifically, we demonstrated how temperature dependent activity patterns of large-bodied bream influenced sediment resuspension, i.e. water turbidity, on a daily basis. Peaks in bream activity occurred, as expected, mainly during summer, but some bream activity persisted even at low temperatures. This is in line with other studies that have shown that lentic fish can be relatively active during the winter season (Jacobsen et al., 2002; Baktoft et al., 2012). The present study aligns with previous studies, suggesting a relationship between presence of bream and water turbidity (Andersson et al., 1978; Breukelaar et al., 1994; Winkel and Davids, 1985; Meijer et al., 1990). However, none of these studies have included seasonal variation and the majority have been conducted under experimental conditions, i.e. in relatively small enclosures. Further, these studies have not strictly focused on the daily relationship between bream activity and resulting changes in turbidity, but instead on more general relationships, e.g. between averages of bream biomass and corresponding water turbidity. Accordingly, this is to our knowledge the first full-scale study under natural conditions to describe seasonal patterns in bream activity and directly demonstrate how increased bream activity influence lake turbidity on a day-to-day and full-scale basis. In relation to this, we assume that bream $>30 \mathrm{~cm}$ constitute the major share of benthivorous fish in our study lake and that it is unlikely that the relationship between bream and FTU is confounded by other benthivorous species. Although we acknowledge that other species present in the lake, e.g. roach and perch, can be benthivorous from time to time, we would argue that their relative lower overall biomass compared to large bream and their lack of protrusion mouth and consequent reduced benthivorous feeding efficiency (Lammens and Hoogenboezem, 1991) makes this assumption valid.

From a lake ecosystem perspective, it is interesting that our results predict that bream activity influence turbidity only when water temperature is relatively low, i.e. below $15^{\circ} \mathrm{C}$. For example, no turbidity below 15-20 FTU (i.e. Secchi depths above $60 \mathrm{~cm}$; Fig. 4), was registered when the bream activity index increased to above 10 pr. day at temperatures below $15^{\circ} \mathrm{C}$ (Fig. 5a). Hence, bream activity in the cold period likely caused considerable variations in light penetration through the water column in Lake Loldrup during the four-year study period.

Previous studies have shown that benthivorous fish including bream (Breukelar et al., 1994; Zambrano et al., 2001; Parkos et al., 2003) can have negative effects on abundance of submerged macrophytes i.e. because of impaired light conditions due to resuspended material as well as through uprooting of plants. The observed general high activity of bream during the cold period and the resulting effect on water turbidity, suggests that such effects can occur even during the winter season. We
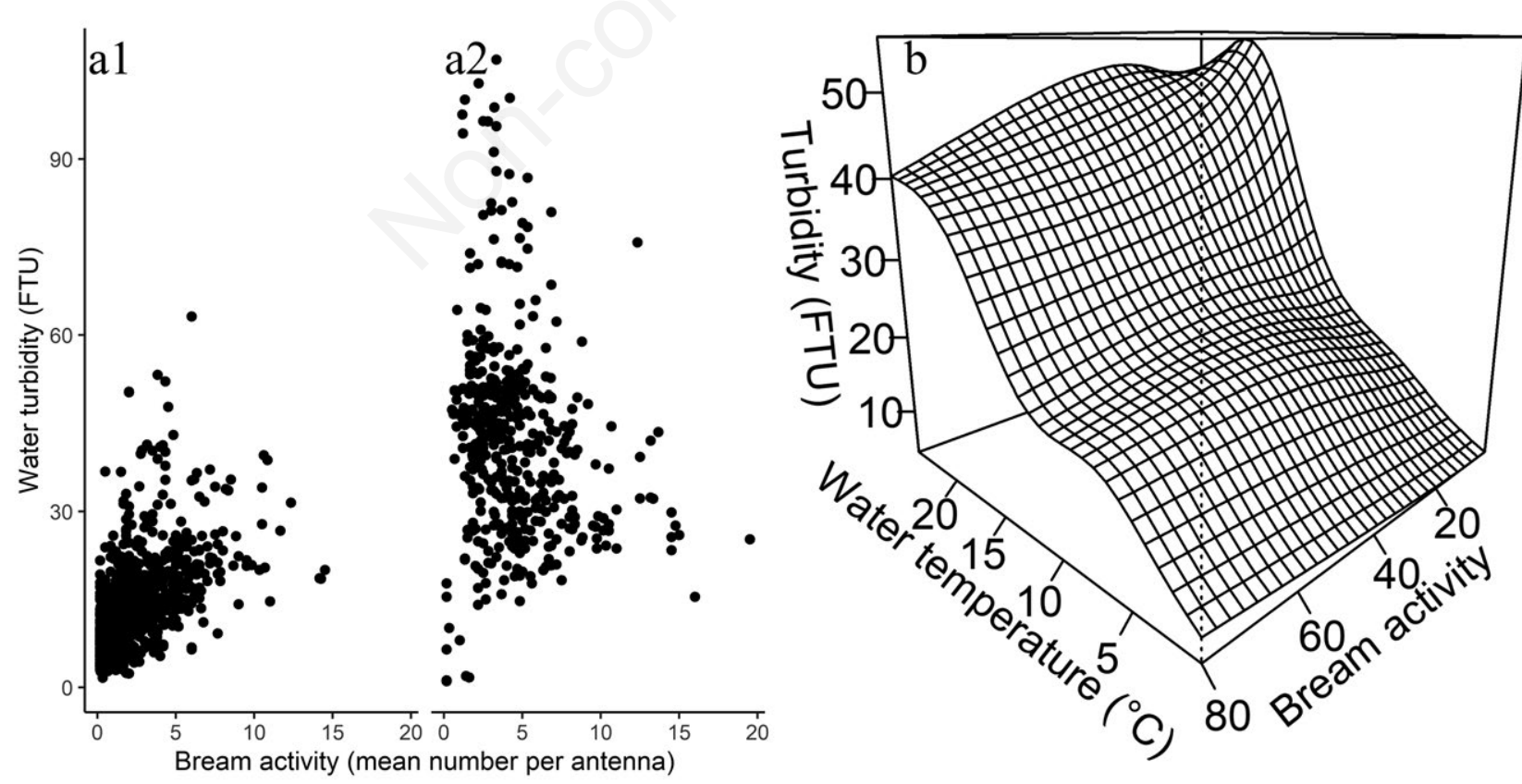

Fig. 5. The relationship between bream activity and water turbidity (FTU) shown as raw data separated between days where average temperature was below (a1) and above $15^{\circ} \mathrm{C}(\mathrm{a} 2)$ and 3D plot showing the model output of how the interaction of water temperature and bream activity (n) predicts turbidity (b). 
tentatively suggest that the negative effects by bream in fact could be most profound during spring when the submerged macrophytes are small and depend on optimal light conditions near the sediment surface. In addition to shading of light through the water column, the establishment of macrophytes could also be impaired directly by spring bream activity. During spring, young macrophytes are more fragile and therefore under higher risk to suffer from uprooting (King and Hunt, 1967). It is well established that submerged macrophytes play an important role in stabilizing shallow lakes in a clear-water state (Scheffer et al., 1993; Jeppesen et al., 1997) i.e. they bind nutrients and reduce sediment resuspension by wind (Donk and Bund, 2002; Nurminen and Horppila, 2009). Hence, winter season activity of bream may therefore play a role for maintaining lakes in a turbid state, by preventing spring establishment of submerged macrophytes. Ultimately, this can lead to reduced biodiversity as submerged macrophytes promote species diversity by providing habitat and food for a range of organisms (Declerck et al., 2007).

Winter activity of bream and related resuspension of sedimentary nutrients, may also play a role for maintaining a turbid state. In general, benthivorous fish may provide an important link between the pelagic and benthic systems of the lake ecosystem, e.g. by bringing nutrients from the benthic to the pelagic zone (Lamarra, 1975; Andersson et al., 1988; Vanni, 2002; Huser et al.,
2016) Hence, it is likely that winter activity of bream may result in increased growth of algal biomass as soon as water temperatures allow for this in spring.

This study found no relationship between bream activity and turbidity at temperatures above $15^{\circ} \mathrm{C}$. This does not mean that such relationship is non-existing at higher temperatures as several studies have measured impacts of bream biomass on water turbidity at temperatures above $15^{\circ} \mathrm{C}$ (Breukelaar et al., 1994; Meijer et al., 1990). Instead, we suggest that phytoplankton productivity in Lake Loldrup became the main driver of turbidity during summer, potentially obscuring any additive effects of increased sediment suspension caused by bream. In relation to this, we recommend that any future study of this kind include a fractionation of the measured turbidity, i.e. separation into phytoplankton and inorganic suspended solids, respectively. Clearly, this will be a useful supplement to the FTU vs Secchi depth calibration that the present study is built on, and give more knowledge on the role of bream activity on turbidity during summer.

Due to logistic issues, it was only possible to place the PIT antennae relatively close to the shoreline, which potentially could lead to bias in our measurements of activity, i.e. if spatial activity patterns vary over the years. A recent telemetry study suggests that seasonal variation in bream habitat use could take place, e.g. Jurajda et al. (2018) found that bream similar to the size of bream in
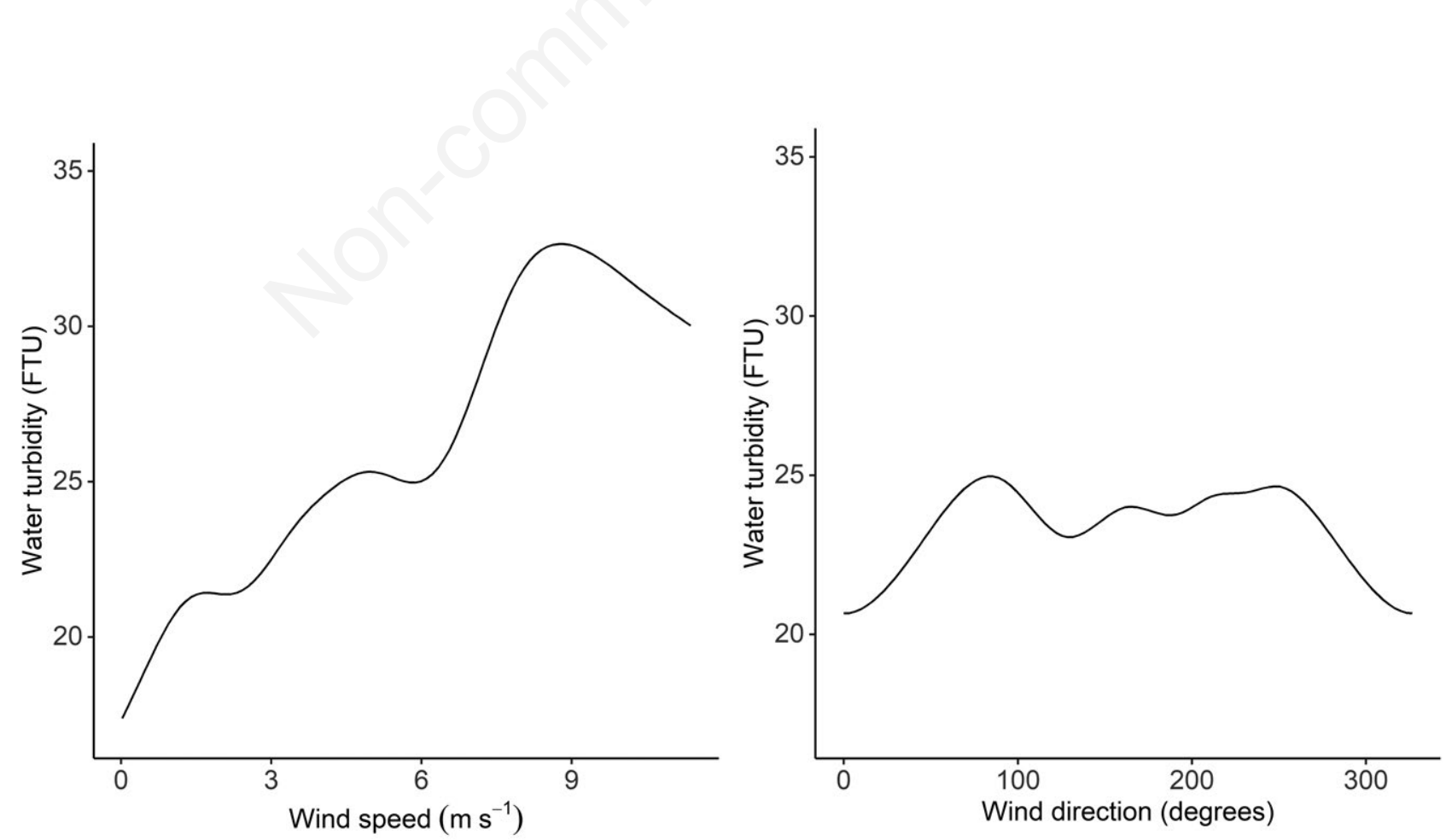

Fig. 6. Model plot of the relationship between wind speed $\left(\mathrm{m} \mathrm{s}^{-1}\right)$, wind direction (degrees) and water turbidity with temperature and bream activity held constant. 
this study, preferred depths between 3-5 meters during winter and avoided depths at 1-2 meter and 5-8 meters. However, if depth variation is the driver behind such seasonal variation, it seems unlikely to influence the results obtained from this study as Lake Loldrup is shallower and has a relative uniform depth profile. Moreover, the results from Jurajda et al. (2018) could be biased by strong individual variability as the spatial behaviour of only eight bream were included in their study. Still, if bream for some reason occasionally avoided the shoreline areas and the PIT antennae during summer, this could add an additional explanation to why we find no clear relationship between bream and FTU during summer.

Our study and statistical analyses were designed to elucidate the role of bream activity and temperature on water turbidity with inclusion of wind conditions as factors. Especially wind conditions have in many studies been shown to affect turbidity through resuspension of sediment especially in large shallow lakes (Kristensen et al., 1992; Eleveld, 2012; Chung et al., 2009; Meijer et al., 1990; Huser et al., 2016). However, since Lake Loldrup is a small lake with the longest fetch of only $800 \mathrm{~m}$ and since this is north-south orientated and the prevailing wind direction is west-east, we did not anticipate wind to play any major role for turbidity in this study. However, there appeared to be a clear relationship between wind speed and water turbidity suggesting that even in small shallow lakes wind induced resuspension can play an important role. Moreover, the strongest effect was seen when the wind was in the prevailing west/east direction. This is surprising, because the west/east fetch is only around 350 meter and because previous studies have shown that the highest resuspension potential is normally located on the lee side of the prevailing wind directions, i.e. the prevailing winds erode the bottom on one side of the lake, depositing resuspended material predominantly on the opposite side, where it can be resuspended by winds from non-prevailing directions (Lövstedt and Bengtsson, 2008). Since wind appeared to play a larger role than expected, we investigated potential interaction between bream activity and wind speed in the winter season, i.e. the season when bream effects were most significant and the occurrence of high-speed wind incidents most frequent. We used a GAM model including observations when water temperatures $<15^{\circ} \mathrm{C}$, and we expected wind to blur any effects of bream activity at high wind speeds. This examination revealed, rather surprisingly, that bream activity influenced turbidity independently of wind speed, i.e. that the resuspension effects from bream is unaffected of wind speeds, at least up to wind speeds of $10 \mathrm{~m} \mathrm{~s}^{-1}$ (Fig. 7). In relation to the overall influence of wind, the resuspension activities of benthivorous fish may play an enhancing role as they prevent sediment consolidation, which likely increase resuspension in windy periods.

We excluded periods with presumed spawning activity from our data set, as we aimed to explore the relationship between bream activity and turbidity exclusively during periods were feeding was the dominant cause of activity. The exclusion of data was based on the knowledge that bream spawn in spring at temperatures above $14.5^{\circ} \mathrm{C}$ (Poncin et al., 1996). Accordingly, we excluded spawning periods between mid-May to mid-July of varying lengths probably reflecting variation in spawning synchronicity between years (see Fig. 2 and Supplementary Tab. 1). The clear relationship between bream activity and turbidity that we found at temperatures below $15^{\circ} \mathrm{C}$ supports that that we successfully managed to exclude the periods of spawning activity and that the majority of activity data in the dataset was indeed related to foraging.

One could argue that the relationship between bream activity and turbidity is causal in the opposite direction, i.e. it reflects that bream prefer to be active in turbid water, e.g. as a way to reduce predation risk from visual predators. However, bream $>30 \mathrm{~cm}$ have outgrown the gape size of most predators (Skov et al., 2011) and therefore we argue that movements due to predation avoidance probably play a minor role, although we acknowledge that a "ghost of predation past" (Mehner and Hölker, 2004) could have had an influence. Also, if bream activity was dictated solely by water visibility, we would

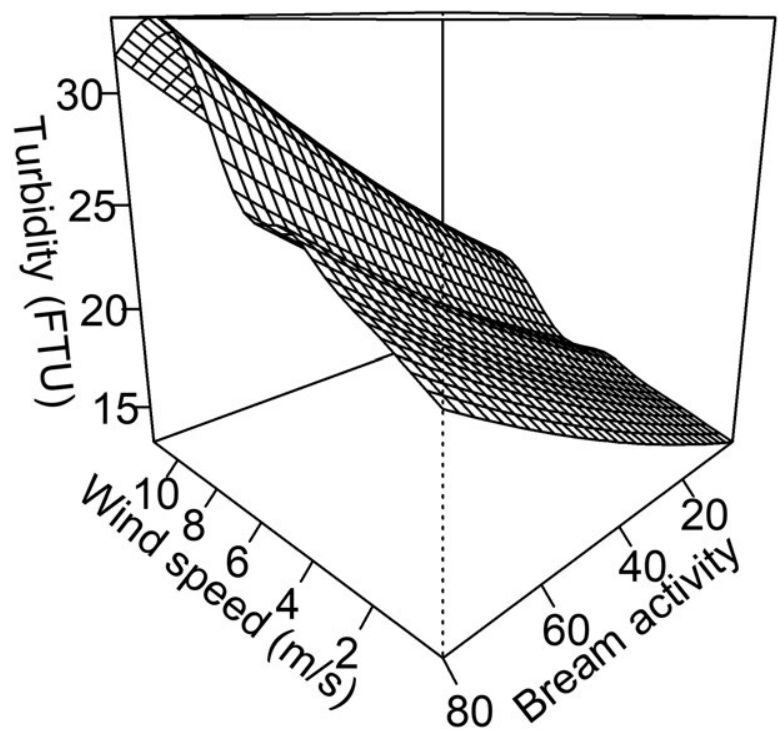

Fig. 7. 3D plot of GAM model illustrating the relationship between wind speed $\left(\mathrm{m} \mathrm{s}^{-1}\right)$ and bream activity (n) at water temperatures below $15^{\circ} \mathrm{C}$. Testing the interaction between bream activity and wind speed shows a non-significant $(\mathrm{P}>0.05)$ relationship. 
have expected to see a clear relationship between FTU and activity also at temperature $>15^{\circ} \mathrm{C}$, where piscivorous fish generally are particularly active, but this was not the case. Finally, at temperatures $<15^{\circ} \mathrm{C}$, where wind speed plays a clear role for FTU this argument would to some extent also predict that bream activity should be high at high wind speeds, but this appeared not to be the case (Fig. 7). However, this prediction could to some extent be confounded by high wind speed incidents during periods with very cold water temperatures, where bream most likely is relative inactive due to metabolic constraints.

Previous studies have demonstrated a link between biomass of bream and turbidity (Breukelar et al., 1994; Meijer et al., 1990). In the present study, we had no information about biomass and could not make this link. However, the population density of tagged bream in Lake Loldrup was most likely not constant throughout the study period as mortality of old individuals probably occurred as did immigrations/emigrations to and from the lake (Brodersen et al., 2019) and furthermore new bream were tagged every year. Still this potential variation in density of tagged bream, which also is partial accounted for in the year effect in the model, was not strong enough to mask the relationship between bream activity and water turbidity, at least at temperatures below $15^{\circ} \mathrm{C}$, which we therefore argue is robust. We assume that turbidity measured with our turbidimeter fixed at a single position in the lake throughout the lake was representative for overall turbidity in the lake. Clearly, it would have been ideal to have had several spatial separated turbidity measurements, but the clear relationship between FTU and Secchi depth, which was measured at two different points in the lake, supports that our single point observation is representative. The lack of information on the stability of bream density clearly impairs discussion of how variation in bream biomass (if any) influenced the fluctuations in turbidity and if any threshold biomass levels should exist where bream biomass would be too low to have impact on turbidity.

\section{CONCLUSIONS}

This study illustrates how non-consumptive effects of large bodied ecosystem engineers can affect aquatic ecosystems and potentially influence the stable state in shallow lakes. More specific we have shown in a fullscale lake study and on a daily basis, how activity of large bodied benthivorous bream influence water turbidity in a small shallow lake, especially at temperatures below $15^{\circ} \mathrm{C}$. This implies that winter season activity of bream may play a role for maintaining lake ecosystems in a turbid state, e.g. by bringing nutrients from the benthic into the pelagic and by preventing spring establishment of submerged macrophytes through shading or mechanical stress. Ultimately, this can lead to reduced biodiversity as submerged macrophytes promote species diversity by providing habitat and food for a range of organisms.

\section{ACKNOWLEDGMENTS}

This project was funded by the Danish National Fishing License Funds. We thank all technicians who helped tag the bream and for monitoring the telemetry system and turbidity logger. Furthermore, we specially thank Anna B. Neuheimer for statistical advice.

\section{REFERENCES}

Andersson G, Berggren H, Cronberg, G, Gelin C, 1978. Effects of planktivorous and benthivorous fish on organisms and water chemistry in eutrophic lakes. Hydrobiologia 59:9-15.

Andersson G, Granéli W, Stenson J, 1988. The influence of animals on phosphorus cycling in lake ecosystems. Hydrobiologia 170:267-284.

Baktoft H, Aarestrup K, Berg S, Boel M, Jacobsen L, Jepsen N, Koed A, Svendsen JC, Skov C, 2012. Seasonal and diel effects on the activity of northern pike studied by highresolution positional telemetry. Ecol Freshw Fish 21:386-394.

Boström B, Jansson M, Forsberg C, 1982. Phosphorus release from lake sediments. Arch. Hydrobiol. Beih Ergebn. Limnol. 18:5-59.

Breukelaar AW, Lammens EHRR, Breteler JGPK, Tátrai I, 1994. Effects of benthivorous bream (Abramis brama) and carp (Cyprinus carpio) on sediment resuspension and concentrations of nutrients and chlorophyll a. Freshwater Biol. 32:113-121.

Brodersen J, Hansen JH, Skov C, 2019. Partial nomadism in large-bodied bream (Abramis brama). Ecol. Freshw. Fish. 28:650-660.

Brönmark C, Hansson L-A, 2002. Environmental issues in lakes and ponds: current state and perspectives. Environ. Conserv. 29:290-306.

Chung EG, Bombardelli FA, Schladow SG, 2009. Sediment resuspension in a shallow lake. Water Resour. Res. 45;W05422. Doi:10.1029/2007WR006585.

Cumming DH, Cumming GS, 2003. Ungulate community structure and ecological processes: body size, hoof area and trampling in African savannas. Oecologia 134:560-568.

Declerck S, Vanderstukken M, Pals A, Muylaert K, Meester LD, 2007. Plankton biodiversity along a gradient of productivity and its mediation by macrophytes. Ecology 88:2199-2210.

Donk EV, Bund WVD, 2002. Impact of submerged macrophytes including charophytes on phyto- and zooplankton communities: allelopathy versus other mechanisms. Aquat. Bot. 72:261-274.

Dublin HT, Sinclair AR, McGlade J, 1990. Elephants and fire as causes of multiple stable states in the Serengeti-Mara woodlands. J. Anim. Ecol. 59:1147-1164.

Eleveld MA, 2012. Wind-induced resuspension in a shallow lake from Medium Resolution Imaging Spectrometer (MERIS) 
full-resolution reflectances. Water Resour. Res. 48:W04508. Doi:10.1029/2011WR011121.

Estes RD, Raghunathan TE, van Vleck D, 2008. The impact of horning by wildebeest on woody vegetation of the Serengeti ecosystem. J. Wildlife Manage. 72:1572-1578.

Fisher JR, Krogman RM, Quist MC, 2013. Influences of native and non-native benthivorous fishes on aquatic ecosystem degradation. Hydrobiologia 711:187-199.

Folke C, Carpenter S, Walker B, Scheffer M, Elmqvist T, Gunderson L, Holling CS, 2004. Regime shifts, resilience, and biodiversity in ecosystem management. Annu. Rev. Ecol. Evol. S 35:557-581.

Gu J, Jin H, He H, Ning X, Yu J, Tan B, Jeppesen E, Li K, 2016. Effects of small-sized crucian carp (Carassius carassius) on the growth of submerged macrophytes: implications for shallow lake restoration. Ecol. Eng. 95:567-573.

Gunderson LH, 2000. Ecological resilience - in theory and application. Annu. Rev. Ecol. Syst. 31:425-439.

Haynes G, 2012. Elephants (and extinct relatives) as earth-movers and ecosystem engineers. Geomorphology 157:99-107.

Huser BJ, Bajer PG, Chizinski CJ, Sørensen PW, 2016. Effects of common carp (Cyprinus carpio) on sediment mixing depth and mobile phosphorus mass in the active sediment layer of a shallow lake. Hydrobiologia 763:23-33.

Ibelings BW, Portielje R, Lammens EHRR, Noordhuis R, van den Berg MS, Joosse W, Meijer ML, 2007. Resilience of alternative stable states during the recovery of shallow lakes from eutrophication: Lake Veluwe as a case study. Ecosystems 10:4-16.

Jacobsen L, Berg S, Broberg M, Jepsen N, Skov C, 2002. Activity and food choice of piscivorous perch (Perca fluviatilis) in a eutrophic shallow lake: a radio-telemetry study. Freshwater Biol. 47:2370-2379.

Jagtman E, Hosper SH, Meijer M-L, van Donk E, 1990. The role of fish stock management in the control of eutrophication in shallow lakes in The Netherlands. Management of Freshwater fisheries, p. 328-343. Proceedings of a Symposium organized by the European Inland Fisheries Advisory Commission.

Jeppesen E, Jensen JP, Søndergaard M, Lauridsen T, Pedersen LJ, Jensen L, 1997. Top-down control in freshwater lakes: the role of nutrients state, submerged macrophytes and water depth. Hydrobiologia 342/343:151-164.

Jeppesen E, Søndergaard M, Jensen JP, Havens KE, Anneville O, Carvalho L, Coveney MF, Deneke R, Dokulil MT,Foy B, Gerdeaux D, Hampton SE, Hilt S, Kangur K, Köhler J, Lammens EHHR, Lauridsen TL, Manca M, Miracle MR, Moss B, Nõges P, Persson G, Phillips G, Portielje R, Romo $\mathrm{S}$, Schelske CL, Straile D, Tatrai I, Willén E, Winder M, 2005. Lake responses to reduced nutrient loading - an analysis of contemporary long-term data from 35 case studies. Freshwater Biol. 50:1747-1771.

Jones CG, Lawton JH, Shachak M, 1997. Positive and negative effects of organisms as physical ecosystem engineers. Ecology 78:1946-1957.

Jurajda P, Roche K, Halačka K, Mrkvová M, Zukal, J, 2018. Winter activity of common bream (Abramis brama L.) in a European reservoir. Fish. Man. Ecol. 25:163-171.

King DR, Hunt GS, 1967. Effect of carp on vegetation in a Lake Erie marsh. J. Wildlife Manage. 31:181-188.

Knapp AK, Blair JM, Briggs JM, Collins SL, Hartnett DC,
Johnson LC, Towne EG, 1999. The keystone role of bison in North American tallgrass prairie: Bison increase habitat heterogeneity and alter a broad array of plant, community, and ecosystem processes. BioScience 49:39-50.

Kottelat M, Freyhof J, 2007. Handbook of European freshwater fishes. Kottelat, Cornol and Freyhof, Berlin: 646 pp.

Kristensen P, Søndergaard M, Jeppesen E, 1992. Resuspension in a shallow eutrophic lake. Hydrobiologia 228:101-109.

Lamarra VA, 1975. Digestive activities of carp as a major contributor to nutrient loading of lakes. Verhandl. Intern. Ver. Limnol. Theor. Angew. Limnol. 19:2461-2468.

Lammens EHRR, Geursen J, MacGillavry PJ, 1987. Diets shift, feeding efficiency and coexistence of bream (Abramis brama), roach (Rutilus rutilus) and white bream (Blicca bjoerkna) in hypertrophic lakes, p. 153-162. Proceedings of the Fifth Congress of European Ichthyologists.

Lammens EHRR, Hoogenboezem W, 1991. Diets and feeding behaviour, p. 353-376. In: I.J. Winfield and J.S. Nelson (eds.), Cyprinid fishes: Systematics, biology and exploitation. Chapman \& Hall.

Lövstedt CB, Bengtsson L, 2008. The role of non-prevailing wind direction on resuspension and redistribution of sediments in a shallow lake. Aquat. Sci. 70:304-313.

Mehner T, Hölker F, 2004. Diurnal vertical migration of ciscoes (Coregonus spp.) in a deep lake: Population patterns and individual behaviour. Proceedings of the "Behaviour and Ecology of Freshwater Fish" Conference (Abstract).

Meijer ML, de Haan MW, Breukelaar AW, Buiteveld H, 1990. Is reduction of the benthivorous fish an important cause of high transparency following biomanipulation in shallow lakes? Hydrobiologia 200/201:303-315.

Miner JG, Stein RA, 1993. Interactive influence of turbidity and light of larval bluegill (Lepomis macrochirus) foraging. Can. J. Fish. Aquat. Sci. 50:781-788.

Moore JW, 2006. Animal ecosystem engineers in streams. BioScience 56:237-246.

Nurminen L, Horppila J, 2009. Life form dependent impacts of macrophyte vegetation on the ratio of resuspended nutrients. Water Res. 43:3217-3226.

Parkos III JJ, Santucci VJ Jr, Wahl DH, 2003. Effects of adult common carp (Cyprinus carpio) on multiple trophic levels in shallow mesocosms. Can. J. Fish. Aquat. Sci. 60:182-192.

Persson A, Hansson L-A, 1999. Diet shift in fish following competitive release. Can. J. Fish. Aquat. Sci. 56:70-78.

Peterson CG, Stevenson RJ, 1992. Resistance and resilience of lotic algal communities: importance of disturbance timing and current. Ecology 73:1445-1461.

Peterson G, Allen CR, Holling CS, 1998. Ecological resilience, biodiversity, and scale. Ecosystems 1:6-18.

Poncin P, Philippart JC, Ruwet JC, 1996. Territorial and nonterritorial spawning behaviour in the bream. J. Fish. Biol. 49:622-626.

R Core Team, 2016. R: A language and environment for statistical computing. R Foundation for Statistical Computing, Vienna.

Roberts J, Chick A, Oswald L, Thompson P, 1995. Effect of carp, Cyprinus carpio L., an exotic benthivorous fish, on aquatic plants and water quality in experimental ponds. Mar. Freshw. Res. 46:1171-1180.

Scheffer M, 1990. Multiplicity of stable states in freshwater systems. Hydrobiologia 200/201:475-486. 
Scheffer M, 1998. Ecology of shallow lakes. Chapman \& Hall, London: $357 \mathrm{pp}$.

Scheffer M, Hosper SH, Meijer ML, Moss B, Jeppesen E, 1993. Alternative equilibria in shallow lakes. Trends Ecol. Evol. 8:275-279.

Skov C, Brodersen J, Brönmark C, Hansson L-A, Hertonsson P, Nilsson PA, 2005. Evaluation of PIT-tagging in cyprinids. J. Fish. Biol. 67:1195-1201.

Skov C, Baktoft H, Brodersen J, Brönmark C, Chapman BB, Hansson L-A, Nilsson PA, 2011. Sizing up your enemy: individual predation vulnerability predicts migratory probability. P. Roy. Soc. B-Biol. Sci. 278:1414-8. doi: 10.1098/rspb.2010.2035.

Skov C, Brodersen J, Nilsson PA, Hansson L-A, Brönmark C, 2008. Inter- and size-specific patterns of fish seasonal migration between a shallow lake and its streams. Ecol. Freshw. Fish. 17:1195-1201.

Smith VH, 2003. Eutrophication of freshwater and coastal marine ecosystems: a global problem. Environ. Sci. Pollut. R. 10:126-139.

Søndergaard M, Liboriussen L, Pedersen AR, Jeppesen E, 2008. Lake restoration by fish removal: short- and long- term effects in 36 Danish lakes. Ecosystems 11: 12911305.

Tammi J, Lappalainen A, Mannio J, Rask M, Vuorenmaa J, 1999. Effects of eutrophication on fish and fisheries in Finnish lakes: a survey based on random sampling. Fisheries Manag. Ecol. 6:173-186.

Vašek M, Kubecka J, Sed'a J, 2003. Cyprinid predation on zooplankton along the longitudinal profile of a canyonshaped reservoir. Arch. Hydrobiol. 156: 535-550.

Vanni MJ, 2002. Nutrient cycling by animals in freshwater ecosystems. Annu. Rev. Ecol. Syst. 33:341-370.

Winkel EHT, Davis C, 1985. Bioturbation by cyprinid fish affecting the food availability for predatory water mites. Oecologia 67:218-19.

Wood SN, 2011. Fast stable restricted maximum likelihood and marginal likelihood estimation of semiparametric generalized linear models. J. R. Stat. Soc. B 73:3-36.

Zambrano L, Scheffer M, Martínez-Ramos M, 2001. Catastrophic response of lakes to benthivorous fish introduction. Oikos 94:344-350.

Zuur, AF, Ieno EN, Walker NJ, Saveliey AA, Smith GM, 2009. Mixed effects models and extensions in ecology with R. Springer, New York: 574 pp. 